\title{
DISCURSOS EM DISSENSO: UM OLHAR SEMIOLINGUÍSTICO SOBRE A CONSTRUÇÃO ARGUMENTATIVA E O ENSINO DE LÍNGUA
}

\section{DISCOURSES IN DISAGREEMENT: A SEMIOLINGUISTIC VIEW ON ARGUMENTATIVE CONSTRUCTION AND LANGUAGE TEACHING}

\author{
Glayci Kelli Reis da Silva Xavier ${ }^{1}$ \\ Ilana da Silva Rebello ${ }^{2}$ \\ Nadja Pattresi de Souza e Silva ${ }^{3}$
}

\begin{abstract}
RESUMO: Muito se discute sobre a importância de o professor levar para a sala de aula temas atuais, a fim de possibilitar a formação de alunos mais críticos e participativos na sociedade. No entanto, como desenvolver um trabalho significativo com textos em sala de aula? Quais são os desafios para quem tem o texto como objeto de ensino na contemporaneidade? A partir dessas reflexões/inquietações, com apoio principalmente nos pressupostos teóricos da Semiolinguística de Análise do Discurso, de Charaudeau, o trabalho em tela tem por objetivo analisar a construção argumentativa e os imaginários sociodiscursivos em tiras do Armandinho e em um texto jornalístico sobre o tema da privatização. Por meio da análise da construção dos argumentos e contra-argumentos e dos imaginários sociodiscursivos que engendram os discursos favoráveis ou contrários à privatização, com este trabalho, espera-se contribuir para o ensino da compreensão da significação indireta (CHARAUDEAU, 2018) e, por consequência, para a formação de leitores críticos.
\end{abstract}

PALAVRAS-CHAVE: Argumentação. Semiolinguística. Imaginários sociodiscursivos. Privatização. Ensino de língua.

ABSTRACT: It is extensively discussed the importance of raising current issues in the classroom environment to mould critical students who can really participate in society. However, how can a meaninful text approach be developed nowadays? What are the challenges for those who take texts as their teaching object? Considering these questions, based on the theoretical principles of Charaudeau's Semiolinguistics Discourse Analysis perspective, the main purpose of the present study is to analyze the argumentative construction and the sociodiscursive imaginaries in comic strips featuring Armandinho and in a journalistic text about privatization. By analyzing the construction of arguments and counterarguments and the sociodiscursive imaginaries which produce favorable and unfavorable discourses about privatization, this text is intended to contribute to the teaching and learning of the indirect signification comprehension (CHARAUDEAU, 2018) and, as a consequence, to the formation of critical readers.

KEYWORDS: Argumentation. Semiolinguistics. Sociodiscursive imaginaries. Privatization. Language teaching.

\footnotetext{
${ }^{1}$ Doutora em Estudos de Linguagem e Professora Adjunta de Língua Portuguesa do Instituto de Letras da Universidade Federal Fluminense (UFF). E-mail: glaycikelli@id.uff.br.

${ }^{2}$ Doutora em Letras e Professora Associada de Língua Portuguesa do Instituto de Letras da Universidade Federal Fluminense (UFF). E-mail: ilanarebello@id.uff.br.

3 Doutora em Estudos de Linguagem e Professora Adjunta de Língua Portuguesa do Instituto de Letras da Universidade Federal Fluminense (UFF). E-mail: nadja_pattresi@id.uff.br.
} 


\title{
PERcursos Linguísticos • Vitória (ES) •v. 11 •n. 29 • 2021 • ISSN: 2236-2592 • Dossiê \\ temático $\bullet O$ texto na pesquisa e no ensino: conhecimentos, práticas e desafios na contemporaneidade •
}

\section{Introdução}

\begin{abstract}
Aprender a argumentar é a pedagogia mais profunda da vida do estudante, porque ele constitui-se, ao mesmo tempo, pesquisador e cidadão. [...] Não basta apenas expô-lo aos gêneros argumentativos, uma vez que, para que ele compreenda de que maneira se constrói a argumentação dentro de cada texto, faz-se necessário que o professor o oriente a levá-lo a identificar o tema abordado, as condições em que o discurso é produzido e o modo como o autor constrói a argumentação em relação ao gênero utilizado.
\end{abstract}

Pedro Demo (2009, p. 79).

No dia a dia, não é difícil encontrar professores que falam que os alunos apresentam muitas dificuldades quando o assunto é compreender o que leem. Por mais incoerente que possa parecer, viver a era da informatização e estar conectado não significa necessariamente ser leitor. Jovens e adolescentes estão, cada vez mais, buscando leituras fáceis, rápidas e resumidas. Como, então, desenvolver um trabalho frutífero com textos em sala de aula e efetivamente despertar o interesse dos alunos pela leitura? Quais são os desafios para quem tem o texto como objeto de ensino na contemporaneidade?

A BNCC, um dos documentos oficiais que norteia a Educação Básica no Brasil, advoga pela necessidade de o ensino de língua portuguesa ser centrado no texto - "Tal proposta assume a centralidade do texto como unidade de trabalho [...]" (BRASIL, 2017, p. 67), sem, no entanto, tomá-lo como pretexto para o ensino de gramática, mas

[...] Os conhecimentos sobre os gêneros, sobre os textos, sobre a língua, sobre a norma-padrão, sobre as diferentes linguagens (semioses) devem ser mobilizados em favor do desenvolvimento das capacidades de leitura, produção e tratamento das linguagens, que, por sua vez, devem estar a serviço da ampliação das possibilidades de participação em práticas de diferentes esferas/ campos de atividades humanas. (BRASIL, 2017, p. 67)

Defende-se, dessa maneira, que o trabalho com o texto seja uma espécie de passaporte, que, além de propiciar o letramento, permita ao aluno participar, de forma crítica, de diferentes áreas sociais. Além disso, retomando a epígrafe, cabe ressaltar que é importante expor o aluno a diferentes gêneros que expressam opinião para que possa desenvolver sua autonomia, ter seus próprios julgamentos e não ser facilmente conduzido pelos imaginários dominantes de determinado grupo social. Como afirma Charaudeau (2016, p. 34), "todo ponto de vista, todo julgamento, tem seu contrário" e, portanto, diante de um mesmo fato, "os indivíduos veem coisas diferentes, não sentem as mesmas emoções, não veem as mesmas causas e fazem julgamentos que lhes são próprios". Dessa maneira, o estudo da argumentação pode levar o indivíduo a se expressar melhor com relação a suas próprias visões e à visão do outro.

Nesse sentido, a partir dessas reflexões iniciais, este estudo, baseado principalmente na teoria Semiolinguística de Análise do Discurso, criada pelo professor emérito da Universidade 


\section{PERcursos Linguísticos • Vitória (ES) •v. 11 •n. 29 • 2021 • ISSN: 2236-2592 • Dossiê temático $\bullet O$ texto na pesquisa e no ensino: conhecimentos, práticas e desafios na contemporaneidade •}

Paris XIII Patrick Charaudeau, visa a contribuir com o ensino de leitura, por meio do cotejo de dois gêneros - tira de jornal e artigo de opinião - que versam sobre o mesmo tema - a privatização de instituições públicas - e trazem em si opiniões antagônicas, destacando o modo argumentativo de organização do discurso e os imaginários sociodiscursivos. Com o estudo proposto, pretende-se mostrar que é possível desenvolver um trabalho significativo com textos em sala de aula.

\section{Semiolinguística: contrato, estratégias e imaginários}

De acordo com o professor Charaudeau (2008, p. 68), texto representa "o resultado material do ato de comunicação e [que] resulta de escolhas conscientes (ou inconscientes) feitas pelo sujeito falante dentre as categorias de língua e os modos de organização do discurso, em função das restrições impostas pela situação" e comunicar "é proceder a uma encenação. [...] [O] texto, para produzir efeitos de sentido visando um público imaginado por ele, o locutor seja ao falar ou ao escrever - utiliza componentes do dispositivo da comunicação em função dos efeitos que pretende produzir em seu interlocutor."

Assim posto, para a Semiolinguística, todo ato de linguagem é uma encenação, chamada de mise en scène, da qual participam, no mínimo, quatro sujeitos - dois parceiros, externos ao texto, seres sociais: o eu-comunicante (EUc) e o tu-interpretante (TUi), e dois protagonistas, internos ao texto, seres discursivos: o eu-enunciador (EUe) e o tu-destinatário (TUd). Pensando no gênero textual artigo de opinião, o eu-comunicante é aquele que detém a iniciativa do ato de produzir o texto, o jornalista que assina a matéria. Ao planejar o texto, esse sujeito comunicante põe em cena um eu-enunciador - a identidade que assume no texto, e idealiza um interlocutor, o tu-destinatário, que pode coincidir ou não com o tu-interpretante, aquele que efetivamente lê o artigo. Por essa razão, Charaudeau (2008) diz que todo ato de linguagem é uma expedição e uma aventura:

[...] aventura é o que está inscrito no campo do imprevisível. Se, de um lado, o sujeito comunicante é senhor de sua encenação, do outro lado (o da recepção propriamente dita), ocorre o contrário: (i) o sujeito interpretante pode não dominar completamente os efeitos produzidos na instância de comunicação do sujeito comunicante; voltamos a lembrar que o EUc tem controle total apenas sobre o destinatário, ou seja TUd; (ii) mas, pode também ocorrer que o sujeito comunicante não seja capaz de dominar seu próprio inconsciente e deixe transparecer evidências que não estão contidas em seus atos de linguagem; em outras palavras, pode produzir, no sujeito-interpretante efeitos não previstos ou desejados; e, por fim, cabe lembrar (iii) que, muitas vezes, o sujeitointerpretante não está totalmente consciente do contexto sócio-histórico que deu origem ao ato de comunicação, o que pode alterar, consideravelmente, sua interpretação. (CHARAUDEAU, 2008, p. 57) 


\section{PERcursos Linguísticos • Vitória (ES) •v. 11 •n. 29 • 2021 • ISSN: 2236-2592 • Dossiê temático $\bullet O$ texto na pesquisa e no ensino: conhecimentos, práticas e desafios na contemporaneidade •}

Comunicar, portanto, é uma aposta, pois o sujeito que comunica, a despeito de respeitar o contrato do gênero e de utilizar estratégias, pode não ser compreendido como pensava e, consequentemente, o texto não produzirá o efeito desejado.

A noção de contrato, termo emprestado do discurso jurídico, prevê um acordo entre os sujeitos sobre as representações linguageiras das práticas sociais. Os sujeitos envolvidos na mise en scène do ato de linguagem precisam levar em consideração quem são os parceiros, se estão face a face, se são únicos ou múltiplos, o canal utilizado para a transmissão e os imaginários culturais e saberes compartilhados, por exemplo.

Dessa maneira, ao produzir o artigo de opinião, o jornalista, se quiser lograr êxito em sua comunicação, precisa atender ao que prevê o contrato do gênero - gênero textual veiculado, normalmente, em jornais, revistas e sites da internet, e, por ser argumentativo, inclui as opiniões e interpretações do jornalista, análises de dados e pesquisa, causas e consequências, dados estatísticos, dentre outras características, a respeito de temas da atualidade. Assim, ao colocar em cena um eu-enunciador, “[...] a instância midiática impõe ao cidadão uma visão de mundo previamente articulada, sendo que tal visão é apresentada como se fosse a visão natural do mundo. [...]" (CHARAUDEAU, 2006a, p. 151) e isso porque, ao lado das restrições impostas pelo contrato, todo ato de linguagem também prevê um espaço de liberdade, que possibilita àquele que comunica a utilização de estratégias, agrupadas, por Charaudeau (2009), sob três rótulos: legitimação, credibilidade e captação.

O jornal procura legitimar-se como um veículo de comunicação sério, comprometido com a instância cidadã e com a verdade dos fatos. O eu-comunicante, com o projeto de texto, deve demonstrar que tem aptidão para desempenhar uma determinada identidade social. Por exemplo, um jornalista, porta voz do jornal, deve construir uma imagem de veículo de comunicação imparcial e confiável. Não é à toa que a mídia utiliza o recurso linguístico citação, que funciona, estrategicamente, como uma fonte de verdade.

Ao lado da estratégia de legitimação, o eu-comunicante também pode adotar atitudes de neutralidade, de distanciamento e de engajamento, que resultarão em credibilidade. Normalmente, o leitor espera de um veículo de comunicação uma postura neutra, objetiva, no entanto, não é difícil que, em meio à concorrência, os jornais demonstrem, de forma explícita, um engajamento diante daquilo que enunciam.

Por último, ainda no espaço de liberdade, o sujeito que comunica pode ter por objetivo principal a captação e, para isso, pode se valer das atitudes de sedução - quando induz o interlocutor a sentir que ele será o beneficiário ao consumir o jornal, de polêmica - quando 


\section{PERcursos Linguísticos • Vitória (ES) •v. 11 •n. 29 • 2021 • ISSN: 2236-2592 • Dossiê temático $\bullet O$ texto na pesquisa e no ensino: conhecimentos, práticas e desafios na contemporaneidade •}

reporta opiniões diferentes sobre um mesmo assunto, e de dramatização - quando apela para o estado emocional do interlocutor.

O espaço de liberdade, assim, permite ao eu-comunicante encenar "suas intenções de forma a produzir determinados efeitos - de persuasão ou de sedução ${ }^{4}$ - sobre o sujeito interpretante (TUi), para levá-lo a se identificar - de modo consciente ou não - com o sujeito destinatário ideal (TUd) construído por EUc. [...]” (CHARAUDEAU, 2008, p. 56).

Dessa forma, diante do exposto, é possível identificar a intencionalidade, o que equivale a projeto de fala (CHARAUDEAU, 2008, p. 48), na base de qualquer ato de linguagem. Ler de forma rápida e superficial, sem levar em consideração todo o contexto de produção, nem sempre permite perceber a intencionalidade de quem produziu o ato de linguagem e as escolhas linguageiras que dão conta dos efeitos. Há de se enfatizar que:

as palavras nada significam em si. Isoladas, só apontam para o que dizem, não para o que significam. Pois há as palavras e o que está implícito nas palavras, e o que está implícito nas palavras depende de outras palavras, das condições em que foram enunciadas, de sua enunciação. É na situação de enunciação que as palavras revelam os pensamentos, as opiniões e as estratégias daquele que as emite. (CHARAUDEAU, 2016, p. 21).

Posto isso, frente ao desafio de perceber a intencionalidade propulsora de um texto e de se alcançar, por meio de inferências interpretativas, a compreensão da significação indireta ${ }^{5}$, é preciso identificar os imaginários que se tem do social, da cultura da qual os indivíduos não só fazem parte, mas que também constroem. Nesse sentido, em todo ato de linguagem, as interpretações da realidade são feitas a partir dos saberes de crença e de conhecimento produzidos e partilhados pelos membros de um mesmo grupo. Esses saberes configuram-se em diversos imaginários sociodiscursivos, que "dão testemunho das identidades coletivas, da percepção que os indivíduos e os grupos têm dos acontecimentos, dos julgamentos que fazem de suas atividades sociais". (CHARAUDEAU, 2006b, p. 207).

Partindo do conceito de imaginário social introduzido por Castoriadis entre os anos 60 e 70, Charaudeau (2006b) acrescenta o elemento discursivo, pois, segundo o semiolinguista,

[...] os grupos sociais produzem discursos de configuração diversa que dão sentido a essas materializações. Uns se fixam em textos escritos (ou na tradição oral) de maneira

\footnotetext{
4 Segundo Charaudeau (2009, s/p), persuadir é "fazer pensar recorrendo à razão" e seduzir é "fazer sentir recorrendo à emoção".

${ }^{5}$ De acordo com Charaudeau (2018), a compreensão é o resultado total da apreensão de um texto e pode concentrarse no conhecimento do idioma - compreensão do sentido literal, ou no conhecimento obtido a partir da relação estabelecida entre enunciados/circunstâncias de produção/recepção do ato de linguagem - compreensão da significação indireta. Para um maior aprofundamento, recomenda-se a leitura do capítulo "Da interpretação à compreensão de textos", de Beatriz Feres, parte da obra Semiolinguística aplicada ao ensino, publicada pela editora Contexto, em 2021.
} 


\title{
PERcursos Linguísticos • Vitória (ES) •v. 11 •n. 29 • 2021 • ISSN: 2236-2592 • Dossiê temático $\bullet O$ texto na pesquisa e no ensino: conhecimentos, práticas e desafios na contemporaneidade •
}

\begin{abstract}
mais ou menos imutável e assim podem ser transmitidos de geração em geração: as doutrinas religiosas, as teorias científicas, os manifestos políticos ou literários. Outros circulam nas comunidades sob configurações variáveis, às vezes mais estáveis, como os provérbios, as máximas e os ditados, às vezes menos, como os torneios de linguagem ou as frases circunstanciais, mas cuja variedade não altera seu sentido de base contido em uma espécie de núcleo semântico mais estável; [...] Esses textos, ditados, slogans, enunciados diversos, são apresentados de maneira simples, pois devem ser compreendidos pela maioria, e desempenham diversos papéis de apelo, de manifesto, de acusação, de potência, de reivindicação. Daí o qualificativo "discursivo" para caracterizar esses imaginários sociais. (CHARAUDEAU, 2006b, p. 206-207).
\end{abstract}

De forma mais específica, de acordo com Charaudeau (2006b, p. 197), os saberes de conhecimento "dizem respeito aos fatos do mundo e à explicação que se pode dar sobre o porquê ou o como desses fenômenos." São provenientes, assim, de uma razão científica que procura explicar a realidade a partir de dados objetivos. Esse tipo de saber é muito utilizado em textos jornalísticos para criar um efeito de credibilidade.

Ao contrário, os saberes de crença são aqueles que procedem de um juízo, de uma avaliação do sujeito que comunica a respeito dos fatos e "o sujeito que fala faz sua escolha segundo uma lógica do necessário e do verossímil, na qual pode intervir tanto a razão quanto a emoção. [...]" (CHARAUDEAU, 2006b, p. 198). Neste ponto, vale a pena lembrar que

[...] o contrato de informação midiática é, em seu fundamento, marcado pela contradição: finalidade de fazer saber, que deve buscar um grau zero de espetacularização da informação, para satisfazer o princípio de seriedade ao produzir efeitos de credibilidade; finalidade de fazer sentir, que deve fazer escolhas estratégica apropriadas à encenação da informação para satisfazer o princípio de emoção ao produzir efeitos de dramatização. (CHARAUDEAU, 2006a, p. 92).

Assim, concluindo essa primeira seção, pelo que foi apresentado até aqui, fica latente a importância da adequação dos atos de falar/escrever às restrições do gênero e da situação de comunicação como um todo, da escolha das estratégias que melhor dão conta do projeto de texto e dos imaginários sociodiscursivos que podem corroborar os sentidos pretendidos. Por outro lado, da parte da instância receptora, cabe identificar as estratégias utilizadas na transformação de categorias linguísticas em categorias discursivas, impregnadas de intencionalidades, para um começo de trabalho relevante com a escrita/fala e a compreensão de textos, pois

a leitura aprofundada de diferentes gêneros textuais deve ser um passaporte para a interação com o mundo, não apenas de leitura da palavra, de forma superficial, mas do mundo - como um meio ou, talvez, o meio de interação legítima do Tuinterpretante-aluno com o mundo. A falta de leitura pode levar o indivíduo a ter dificuldade para entender o mundo, a tomar a sua palavra e a agir realmente como sujeito. (REBELLO, 2021, p. 39). 


\section{PERcursos Linguísticos • Vitória (ES) •v. 11 •n. 29 • 2021 • ISSN: 2236-2592 • Dossiê temático $\bullet O$ texto na pesquisa e no ensino: conhecimentos, práticas e desafios na contemporaneidade •}

\section{O que significa argumentar na perspectiva semiolinguística?}

Como um fenômeno de linguagem de múltiplas dimensões, a argumentação é um processo que tem recebido destaque em diferentes perspectivas de estudo e áreas de atuação. Desde a retórica clássica, com base na tríade aristotélica ethos, logo e pathos, às investigações da nova retórica, a que se vinculam, por exemplo, Perelman e Olbrechts-Tyteca (2005), e às pesquisas de caráter textual-discursivo, como as divulgadas em Cavalcante et al. (2020), a construção argumentativa e seus mecanismos têm sido objeto de exame. A presente proposta filia-se a este último campo, mais especificamente ao viés desenvolvido pela Semiolinguística, teoria de Análise do Discurso cujas bases centrais já foram apresentadas.

Pela ótica de Charaudeau (2008, p. 68, grifo do autor), a argumentação constitui, junto ao descritivo e ao narrativo, um dos modos de organização do discurso, ou seja, um dos "princípios de organização da matéria linguageira", que "[...] dependem da finalidade comunicativa do sujeito falante". Sustentando essas três formas de organizar o ato de linguagem, considera-se, ainda, o modo enunciativo, uma exclusividade do aporte teóricometodológico da Semiolinguística. Nesse caso, analisam-se as formas como o enunciador se relaciona consigo mesmo, expressando explicitamente seu ponto de vista; com seu interlocutor, interpelando-o diretamente, e com o dito, apagando as marcas de pessoalidade ou recorrendo ao discurso relatado. Para isso, mobilizam-se, respectivamente, três estratégias que sinalizam essas funções enunciativas: a elocução, a alocução e a delocução.

No modo de organização argumentativo, além dessas possibilidades de construção enunciativa, produzem-se uma lógica e uma encenação do dizer para se expressar uma convicção e uma explicação ao interlocutor a fim de "persuadi-lo a modificar seu comportamento" (CHARAUDEAU, 2008, p. 205). Decorrem daí duas importantes constatações. A primeira corresponde ao fato de que a argumentação se sustenta em um tripé que prevê um sujeito argumentante, uma proposta sobre o mundo e um sujeito-alvo. A segunda envolve o reconhecimento de que argumentar abarca uma busca tanto de racionalidade, uma vez que o argumentante se pauta por um ideal de verdade para explicar algo sobre o mundo, quanto de influência, considerando que se mobiliza também um ideal de persuasão cujo fim é levar o destinatário a partilhar determinado universo de discurso, inclusive com recursos descritivos ou narrativos, por exemplo. 


\section{PERcursos Linguísticos • Vitória (ES) •v. 11 •n. 29 • 2021 • ISSN: 2236-2592 • Dossiê temático $\bullet O$ texto na pesquisa e no ensino: conhecimentos, práticas e desafios na contemporaneidade •}

Assim, segundo Charaudeau (2008), o argumentativo se organiza por uma razão demonstrativa e uma razão persuasiva. Aquela compreende a lógica argumentativa, mecanismo por meio do qual se instituem relações de causalidade, de modo geral, entre as asserções sobre o mundo, e esta abrange a encenação argumentativa em si, mecanismo que aciona provas com base em argumentos que sustentam tais proposições.

$\mathrm{Na}$ lógica argumentativa, verificam-se três elementos inter-relacionados de forma explícita ou implícita: uma asserção de partida (A1), que indica um dado ou premissa sobre o mundo; uma asserção de chegada (A2), que corresponde à conclusão que deve ser aceita em razão de A1, e uma asserção de passagem, que reúne um ou mais elementos (provas, argumentos, inferências) que possibilitam associar A1 e A2. Isso se dá com apoio em imaginários sociodiscursivos que devem ser partilhados entre os interlocutores a fim de se provar a validade da relação de causalidade entre a asserção de partida e a de chegada.

Em termos linguísticos, as articulações lógicas entre A1 e A2 podem se estabelecer por diferentes modos de encadeamento, tais como a disjunção $(O u$ se investe nos Correios ou sua precarização será maior); a restrição (Os Correios prestam um serviço essencial, mas não recebem os investimentos necessários), a finalidade (Defende-se a privatização dos Correios para que o serviço se torne mais eficiente) e a consequência (Os Correios não recebem os investimentos necessários à sua modernização, então perdem competitividade no mercado).

Como se disse, para que haja argumentação, essa lógica precisa se inscrever em uma encenação argumentativa. Para isso, mobiliza-se um dispositivo que associa uma (i) proposta ou tese sobre o mundo por meio de uma relação ampla de causalidade; (ii) uma proposição, por meio da qual o sujeito se mostra favorável ou contrário à proposta ou, ainda, assume uma atitude de ponderação e a (iii) persuasão, que explicita o quadro de raciocínio que alicerça a posição assumida pelo sujeito (a de justificativa, a de refutação ou a de ponderação da tese).

Nesse sentido, para fornecer ao destinatário meios de julgar a validade do que está em jogo na argumentação, o sujeito argumentante utiliza-se de diversas estratégias. De acordo com Menezes (2006, p. 96-97, grifo nosso), aciona-se:

[...] um conjunto de procedimentos, que são de ordem semântica (relativos aos valores e domínios de avaliação), discursiva (que consistem no uso de determinadas categorias da língua e no recurso a outros modos de organização, trazendo, por exemplo, a definição, a nomeação, a comparação, a citação, o questionamento, a narrativa etc. [...]) e composicional (que consistem em repartir, distribuir, hierarquizar os elementos do dispositivo argumentativo ao longo do texto, de forma a facilitar o reconhecimento de diferentes articulações do raciocínio ou a compreensão das conclusões da argumentação). 


\section{PERcursos Linguísticos • Vitória (ES) •v. 11 •n. 29 • 2021 • ISSN: 2236-2592 • Dossiê temático $\bullet O$ texto na pesquisa e no ensino: conhecimentos, práticas e desafios na contemporaneidade •}

Essa construção discursiva ancorada em relações de causalidade e na produção de um quadro de raciocínio com fins persuasivos é típica de gêneros argumentativos, como se verá adiante, com a análise de tiras de Armandinho e de um artigo sobre o tema da privatização. Pela circulação social desses gêneros e pela relevância de se desenvolver a capacidade de argumentar, inerente à natureza humana, no ensino básico, algumas possibilidades de abordagem desse processo serão exploradas a seguir.

Assim, pretendemos partilhar alternativas que preencham a lacuna a que Charaudeau (2008, p. 201, grifo do autor), de forma tão pertinente, se refere: "Se as instruções oficiais recomendam que se desenvolvam as capacidades de raciocínio dos alunos, nada é dito sobre o modo de se chegar a isso.”.

\section{Análise semiolinguística da construção de argumentos e contra-argumentos em textos sobre a privatização: a língua em uso}

Argumentar faz parte da vida do ser humano. A criança, desde cedo, sabe "negociar" suas ideias, alegando seu "bom comportamento", a tarefa feita ou mesmo apelando emocionalmente pelo choro. Algo tão natural na vida cotidiana, ao chegar à escola, a argumentação pode parecer distante do aluno, a depender da forma como a abordagem é conduzida. Torna-se necessário, então, planejar e repensar as práticas que envolvem a argumentação na escola. De acordo com a BNCC, uma das competências para a Educação Básica é:

Argumentar com base em fatos, dados e informações confiáveis, para formular, negociar e defender ideias, pontos de vista e decisões comuns que respeitem e promovam os direitos humanos, a consciência socioambiental e o consumo responsável em âmbito local, regional e global, com posicionamento ético em relação ao cuidado de si mesmo, dos outros e do planeta. (BRASIL, 2017, p. 9).

Para o sucesso dessa empreitada, é importante que o estudo da argumentação não fique limitado aos anos finais do Ensino Fundamental ( $8^{\circ}$ e $9^{\circ}$ anos), tampouco ao Ensino Médio. Assim, defende-se que este pode ser desenvolvido desde cedo, por meio de diferentes perspectivas. Como afirmam Dolz e Schneuwly (2004, p. 64), o trabalho com textos na escola deve ocorrer em espiral, ou seja, objetivos semelhantes devem ser "abordados em níveis de complexidade cada vez maiores ao longo da escolaridade". E tal ideia é corroborada pelos documentos oficiais, que apresentam em seu conteúdo, seja direta ou indiretamente, a indicação do trabalho com a argumentação nos diferentes níveis de ensino. 


\section{PERcursos Linguísticos • Vitória (ES) •v. 11 •n. 29 • 2021 • ISSN: 2236-2592 • Dossiê temático $\bullet O$ texto na pesquisa e no ensino: conhecimentos, práticas e desafios na contemporaneidade •}

Contudo, cabe ressaltar que, quando se sugere aqui trabalhar a argumentação desde a fase escolar inicial, não se quer dizer que se deva utilizar, por exemplo, um artigo de opinião ou carta do leitor no $1^{\mathrm{o}}$ ano do Ensino Fundamental. Para além dos gêneros canônicos, a argumentação está presente nos mais variados textos, em diferentes níveis. De acordo com Koch (1998, p. 29), a argumentatividade está inscrita na própria língua, pois, quando se interage por meio da linguagem, há sempre objetivos a serem atingidos: almeja-se estabelecer relações, causar certos efeitos, suscitar comportamentos, ou seja, pretende-se atuar sobre o outro de modo a desencadear determinadas reações. Por isso, para analisar a argumentação produzida na/pela linguagem, é preciso considerar a diversidade e o dinamismo provenientes das mais diversas situações de uso da língua.

Nessa perspectiva, com vistas ao desenvolvimento de um trabalho de leitura e interpretação de textos argumentativos na escola, será apresentada a análise de exemplares que trazem em si um debate de visões opostas, com a proposição de argumentos e contraargumentos sobre o tema "privatização". A análise empreendida aqui pode ser parte de um projeto ou sequência didática, que inclua posteriormente o exercício de construção de argumentos e produção de textos orais e/ou escritos. $\mathrm{O}$ corpus de análise incluirá tirinhas do personagem Armandinho, de Alexandre Beck, e trechos ${ }^{6}$ de um artigo publicado no site da Associação dos Profissionais dos Correios (ADCAP), em que se tenta promover um debate com a sociedade para discutir os argumentos usados pelo governo a favor da privatização da estatal.

A utilização de textos provenientes da esfera midiática também está em consonância com os documentos oficiais que regem o ensino em nosso país, já, que, segundo eles, é importante que os alunos:

[...] incorporem em suas vidas a prática de escuta, leitura e produção de textos pertencentes a gêneros da esfera jornalística em diferentes fontes, veículos e mídias, e desenvolvam autonomia e pensamento crítico para se situar em relação a interesses e posicionamentos diversos. Também estão em jogo a produção de textos noticiosos, opinativos e a participação em discussões e debates de forma ética e respeitosa. (BRASIL, 2017, p. 509)

Observe-se, então, uma sequência de quatro tiras do Armandinho, dispostas na ordem em que foram divulgadas. Os exemplares foram publicados na rede social Facebook, entre 23 e 24 de agosto de 2021, época em que que se intensificou a movimentação do Governo Federal

\footnotetext{
${ }^{6}$ Devido à extensão do presente trabalho, optou-se por utilizar somente trechos do artigo, cotejando o conteúdo com as tiras de Armandinho. O texto integral está disponível em: https://adcap.org.br/index.php/trabalhadoresdos-correios-afirmam-que-argumentos-usados-pelo-governo-a-favor-da-privatizacao-da-estatal-nao-temembasamento/. Último acesso em 27 ago. 2021.
} 
PERcursos Linguísticos • Vitória (ES) •v. 11 •n. 29 • 2021 • ISSN: 2236-2592 • Dossiê temático $\bullet O$ texto na pesquisa e no ensino: conhecimentos, práticas e desafios na contemporaneidade •

para privatizar diversas instituições públicas e mistas, dentre elas os Correios. As tiras estão interligadas entre si e são parte de uma narrativa maior, pois, juntas, contam a mesma história. Nelas, Armandinho e seu amigo Pudim conversam sobre a privatização da "pracinha" onde costumam brincar, apresentando visões opostas sobre o tema.

Nicolau e Magalhães (2013, p. 64) definem as tiras (ou tirinhas) como "uma sequência narrativa em quadrinhos humorística e satírica que utiliza a linguagem verbal e não verbal, transmitindo, em sua grande maioria, uma mensagem de caráter opinativo". Nesse caso, traz em si a visão do cartunista a respeito de determinado assunto, orientando o modo de ver do leitor. Por ser um texto multimodal, que tem seu projeto de dizer semiotizado em diferentes linguagens, a análise começará pela parte visual do texto.

Figura 1 - Tirinhas do Armandinho
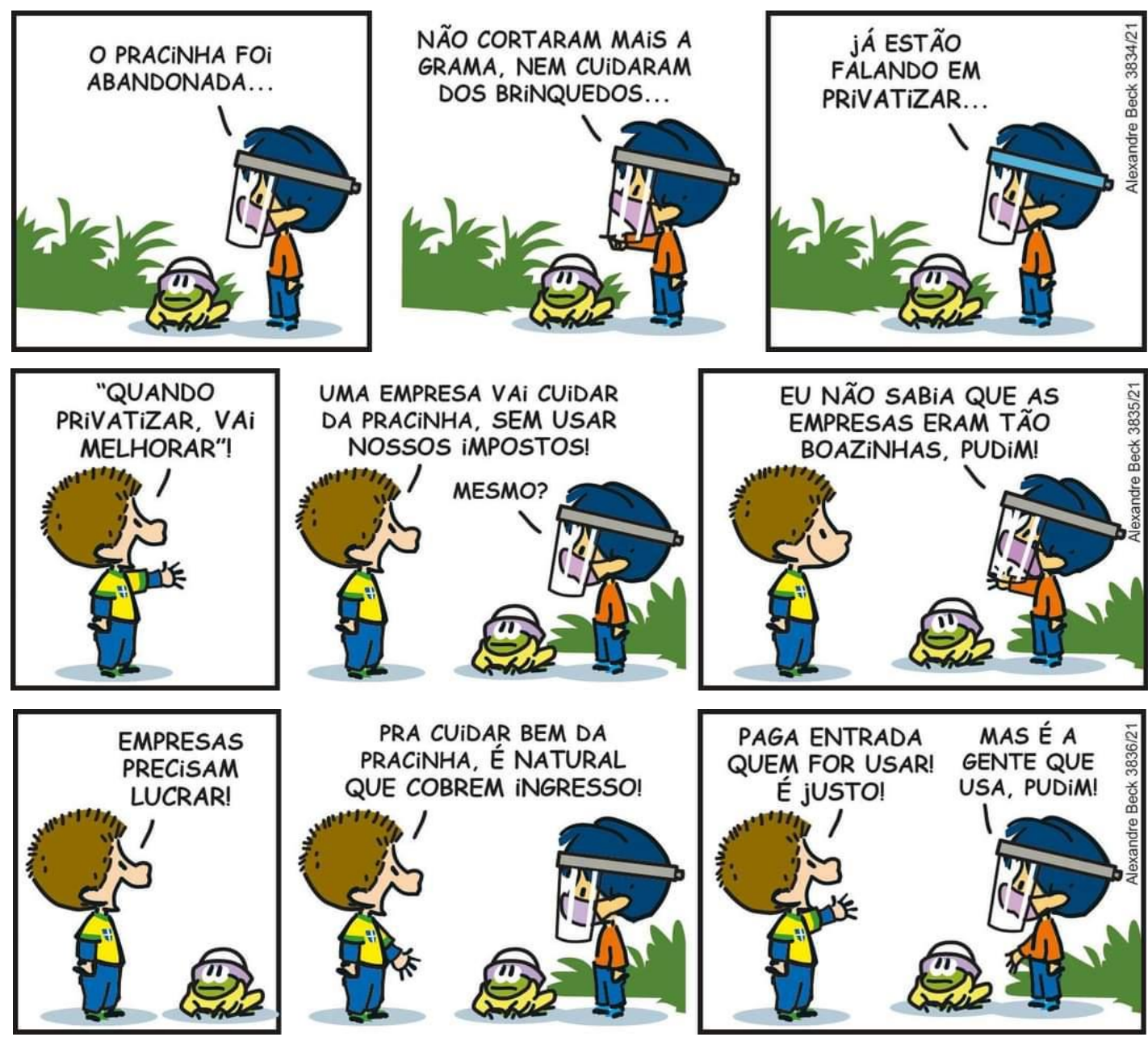


\section{PERcursos Linguísticos • Vitória (ES) •v. 11 •n. 29 • 2021 • ISSN: 2236-2592 • Dossiê temático $\bullet O$ texto na pesquisa e no ensino: conhecimentos, práticas e desafios na contemporaneidade •}
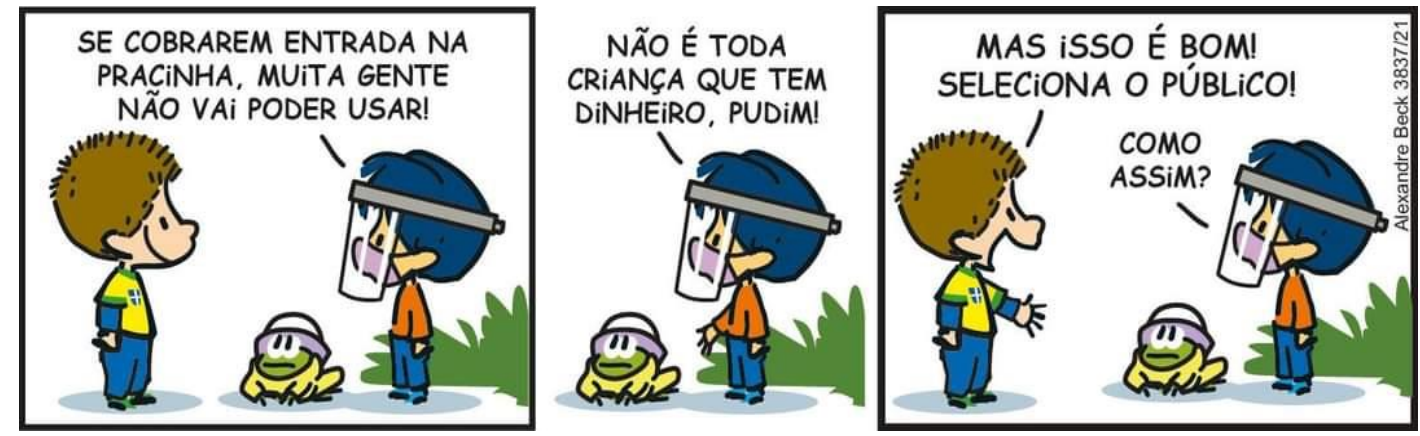

Fonte: BECK, Alexandre. Post em rede social. Florianópolis, SC, agosto, 2021. Facebook. Disponível em: https://www.facebook.com/tirasarmandinho/. Último acesso em: 24 ago. 2021.

Destaca-se, nas imagens, a figura dos personagens que, por suas vestes, já antecipam, de alguma maneira, o posicionamento que irão assumir, revelando a identidade coletiva a que se filiam. Segundo Charaudeau (2016, p. 29), a identidade coletiva tende a ser constantemente defendida, reforçada ou lembrada e, confrontado com a diferença do outro, o grupo tende a diferenciar-se para se afirmar, sentir-se forte (ou até mesmo não ser confundido).

Pudim usa roupas que remetem ao uniforme da seleção brasileira de futebol, adereço do qual os movimentos pró-governo apropriaram-se como símbolo. Além disso, em pleno período de pandemia (2021), o menino está sem máscara, clara alusão aos seguidores do presidente brasileiro, que não defende seu uso ${ }^{7}$. Pudim terá, portanto, um discurso a favor da privatização, já que a posição política do grupo com o qual se identifica é pelo liberalismo, a favor do estado mínimo ${ }^{8}$.

Armandinho, por outro lado, usa máscara e proteção facial (face shield), inclusive em seu sapinho de estimação e, numa visão oposta à do amigo, mostra que se preocupa com a propagação da doença. Apesar de suas roupas não trazerem nenhuma marca específica de grupo político, veremos que seu discurso será contra a privatização. Charaudeau $(2015$, p. 18) afirma que "o pertencimento a um grupo é, em primeiro lugar, o não pertencimento a outro grupo, e a busca do grupo, enquanto entidade coletiva, é igualmente a busca do não outro". No cenário, o

7 Consultar as notícias: "Bolsonaro contraria ciência e diz a apoiadores que eficácia de máscara é 'quase nenhuma", disponível em https://g1.globo.com/politica/noticia/2020/08/19/bolsonaro-contraria-ciencia-e-diz-aapoiadores-que-eficacia-de-mascara-e-quase-nenhuma.ghtml; "Bolsonaro diz que máscaras são 'ficção' e ataca medidas de proteção contra Covid", disponível em https://istoe.com.br/bolsonaro-diz-que-mascaras-sao-ficcao-eataca-medidas-de-protecao-contra-covid/ . Acesso em 23 set. 2021.

${ }^{8}$ Consultar notícia: "Governo anuncia plano para privatizar nove empresas estatais; veja lista", disponível em: https://g1.globo.com/economia/noticia/2019/08/21/governo-anuncia-plano-para-privatizar-nove-empresasestatais.ghtml. Acesso em 23 set. 2021. 


\section{PERcursos Linguísticos • Vitória (ES) •v. 11 •n. 29 • 2021 • ISSN: 2236-2592 • Dossiê temático $\bullet O$ texto na pesquisa e no ensino: conhecimentos, práticas e desafios na contemporaneidade •}

mato alto que cresce ao fundo representa a falta de cuidados com o local, o que reforça a ideia de "abandono".

Agora passemos à parte verbal, pois, afinal, como aponta Charaudeau (2016, p. 10), "é na situação de enunciação que as palavras revelam os pensamentos, as opiniões e as estratégias daquele que as emite". A narrativa se inicia com a contextualização do tema, falando sobre o estado físico da pracinha (qualificação) que, segundo Armandinho, "foi abandonada": "Não cortaram mais a grama, nem cuidaram dos brinquedos". O uso de palavras negativas como "não" e "nem" reforçam a ideia de "abandono". A partir dessa observação, o personagem introduz o tema da privatização: "já estão falando em privatizar...".

Nas tirinhas seguintes, surge Pudim, proferindo argumentos a favor da privatização da pracinha, enquanto Armandinho refuta tais afirmativas, num jogo de argumentação e contraargumentação. Koch e Elias (2017, p. 34) apontam que "toda argumentação é diálogo, porque envolve sujeitos, seus conhecimentos e formas de compreensão da realidade; porque pressupõe liberdade de pensar e expressar o pensamento". Por esse motivo, as autoras reforçam que, no jogo argumentativo, pode não ser suficiente apenas justificar uma tese, mas também “considerar a existência de teses contrárias que podem ser evocadas, citadas, refutadas ou em relação as quais podemos fazer alguma concessão" (KOCH; ELIAS, 2017, p. 34).

Segundo Charaudeau (2008, p. 222), conforme já foi mencionado, dentro do dispositivo argumentativo, por meio de uma proposição, em um quadro de questionamento, coloca-se em causa a proposta (tese), desenvolvendo a argumentação em tal ou qual direção: o sujeito mostrase de acordo (justifica) ou em desacordo com a proposta (refuta). Então, num ato de persuasão, recorre a diversos procedimentos (semânticos, discursivos e de composição) para estabelecer a prova da posição adotada na proposição.

$\mathrm{Na}$ construção da tirinha, o cartunista optou por apresentar as teses a favor da privatização na figura do Pudim e aquelas que as refutam na figura do Armandinho. Dentro do espaço interno ao texto, relativo à interação entre os personagens, tem-se:

- proposta sobre o mundo 1 (implícita): "é preciso privatizar a pracinha";

- sujeito argumentante: Pudim (EUe);

- sujeito-alvo: o Armandinho e os leitores da tirinha, todos idealizados (TUd).

- proposta sobre o mundo 2 (implícita): "Se cobrarem entrada na pracinha, muita gente não vai poder usar! Não é toda criança que tem dinheiro, Pudim!” ( $A$ privatização não é uma coisa boa para todos e prejudica principalmente a parcela pobre da população). 


\section{PERcursos Linguísticos • Vitória (ES) •v. 11 •n. 29 • 2021 • ISSN: 2236-2592 • Dossiê temático $\bullet O$ texto na pesquisa e no ensino: conhecimentos, práticas e desafios na contemporaneidade •}

- sujeito argumentante: Armandinho, dando voz ao cartunista (EUe);

- sujeito-alvo: o Pudim e os leitores da tirinha, todos idealizados (TUd).

Já no espaço externo ao texto, considerando-se sua produção-recepção, tem-se:

- proposta sobre o mundo (implícita): a privatização não é uma coisa boa para todos e prejudica principalmente a parcela pobre da população;

- $\quad$ sujeito argumentante: o cartunista (EUc);

- sujeito-alvo: leitores da tirinha, seres sociais (TUi).

Esquematicamente, em uma visão macrotextual, considerando a tirinha como um todo, pode-se, então, representar a organização dos argumentos por meio do seguinte quadro:

Quadro 1: Argumentos da tirinha

\begin{tabular}{|c|c|}
\hline $\begin{array}{l}\text { Argumentos favoráveis à privatização } \\
\text { (Pudim) }\end{array}$ & $\begin{array}{l}\text { Argumentos contrários à privatização } \\
\text { (Armandinho) }\end{array}$ \\
\hline $\mathrm{XXX}$ & $\begin{array}{l}\text { “A pracinha foi abandonada...” (Há uma } \\
\text { precarização da instituição pública com o intuito de } \\
\text { desqualificá-la e depois vendê-la). }\end{array}$ \\
\hline $\begin{array}{l}\text { “'Quando privatizar, vai melhorar'! Uma empresa vai } \\
\text { cuidar da pracinha, sem usar nossos impostos!” (A } \\
\text { pracinha não é bem cuidada pelo poder público, por } \\
\text { isso é preciso privatizar; impostos são cobrados, mas } \\
\text { não são bem administrados). }\end{array}$ & $\begin{array}{l}\text { “Mesmo? Eu não sabia que as empresas eram tão } \\
\text { boazinhas, pudim!” (As empresas privadas só visam } \\
\text { ao lucro, não fazem nada sem algo em troca). }\end{array}$ \\
\hline $\begin{array}{l}\text { "Empresas precisam lucrar! Pra cuidar da pracinha, é } \\
\text { natural que cobrem ingresso!" (No mundo capitalista, } \\
\text { é assim que funciona: empresas trazem beneficios, } \\
\text { mas precisam lucrar em troca, para valer a pena e } \\
\text { fazerem um bom trabalho). }\end{array}$ & XXX \\
\hline $\begin{array}{c}\text { "Paga entrada quem for usar! É justo!” (Nessa lógica, } \\
\text { só deve usar quem pagar por isso. Quem paga tem } \\
\text { direito aos benefícios). }\end{array}$ & $\begin{array}{c}\text { "Mas é a gente que usa, Pudim! Se cobrarem entrada } \\
\text { na pracinha, muita gente não vai poder usar! Não é } \\
\text { toda criança que tem dinheiro, Pudim!” (Isso vai } \\
\text { restringir o público e prejudicar principalmente os } \\
\text { mais pobres, que não têm condições para custear a } \\
\text { atividade.). }\end{array}$ \\
\hline $\begin{array}{l}\text { "Mas isso é bom! Seleciona o público!" (O fato de } \\
\text { cobrar afastará moradores de rua, assaltantes e } \\
\text { aqueles que depredam o local e que fazem mau uso } \\
\text { dele; somente pessoas "selecionadas" irão usá-lo). }\end{array}$ & $\begin{array}{c}\text { “Como assim?” (Isso aumentará a segregação social } \\
\text { e tirará o benefício dos mais necessitados, que } \\
\text { também têm direito ao lazer). }\end{array}$ \\
\hline
\end{tabular}

Fonte: Criação nossa.

Mesmo que a tirinha direcione a conclusão para a não privatização, o leitor julgará os argumentos que considera mais relevantes e que condizem com a sua ideologia político-social para adotar sua posição. Num movimento dialógico (pois todo texto é lugar de interação), irá concordar, discordar, refletir, reformular. Pensando agora para o nível microtextual, ou seja, para o sentido de língua, que leva ao sentido de discurso, destacam-se, ainda, alguns aspectos. 


\section{PERcursos Linguísticos • Vitória (ES) •v. 11 •n. 29 • 2021 • ISSN: 2236-2592 • Dossiê temático $\bullet O$ texto na pesquisa e no ensino: conhecimentos, práticas e desafios na contemporaneidade •}

A fala de Pudim, em sua primeira aparição, é escrita entre aspas e exemplifica um caso de delocução (discurso relatado). Isso significa que é uma voz coletiva, algo repetido como uma fórmula cristalizada pelo grupo a favor da privatização. Para Charaudeau (2015, p. 26), é por meio da língua que se dá a integração social e que se forja a simbólica identitária; portanto, a língua é necessária à constituição de uma identidade coletiva e garante a coesão de uma comunidade. Além disso, a referência de Armandinho às crianças, indivíduos mais frágeis socialmente, que precisam de proteção e não têm recursos financeiros, pode também ser considerada como simbólica, representando as classes menos abastadas e as minorias.

$\mathrm{Na}$ construção linguística, destacando-se as ideias centrais em debate, a lógica argumentativa se desenvolve nas seguintes relações de causalidade (modos de encadeamento):

1. Consequência: "A pracinha foi abandonada" (A1) $\rightarrow$ logo "estão falando em privatizar" (A2).

2. Causa: "Quando privatizar, vai melhorar" $(\mathrm{A} 1) \rightarrow$ porque "uma empresa vai cuidar da pracinha, sem usar nossos impostos" (A2).

3. Finalidade: "É natural que cobrem ingresso" $\rightarrow$ para "cuidar bem da pracinha".

4. Oposição: "Paga entrada quem for usar! É justo!" (A1 - Armandinho) $\rightarrow$ mas “não é toda criança que tem dinheiro" (A2 - Pudim).

5. Restrição: "Muita gente não vai poder usar" (A1 - Armandinho) $\rightarrow$ mas isso é bom que "seleciona o público" (A2 - Pudim).

Numa gradação de argumentos, considerando-se as relações de causalidade visíveis, pode-se afirmar que os argumentos contra a privatização têm mais peso. Tal ideia se confirma ao considerar que essa é a posição defendida pelo personagem principal da tira, conhecido por sua visão crítica e social, comparado por muitos, com a Mafalda de Quino. Contudo, cabe destacar que a relação de causalidade em seus diferentes modos de encadeamento nunca é puramente formal, visível na superfície textual (CHARAUDEAU, 2009, p. 211). A causalidade pode estar no implícito; depende tanto do conteúdo semântico e das relações de sentido que se estabelecem entre as asserções, quanto das condições lógicas que caracterizam tal relação.

Em seguida, em um movimento comparativo, serão apresentados fragmentos de um artigo sobre o mesmo tema. "Trabalhadores dos Correios afirmam que argumentos usados pelo governo a favor da privatização da estatal não têm embasamento"9 é um texto que versa especificamente sobre a privatização dos Correios, que pretende, como diz o subtítulo abaixo

\footnotetext{
${ }^{9} \mathrm{O}$ texto integral está disponível em: https://adcap.org.br/index.php/trabalhadores-dos-correios-afirmam-queargumentos-usados-pelo-governo-a-favor-da-privatizacao-da-estatal-nao-tem-embasamento/. Último acesso em 27 ago. 2021.
} 


\section{PERcursos Linguísticos • Vitória (ES) •v. 11 •n. 29 • 2021 • ISSN: 2236-2592 • Dossiê temático $\bullet O$ texto na pesquisa e no ensino: conhecimentos, práticas e desafios na contemporaneidade •}

do título, "promover um debate com a sociedade para discutir o tema". O texto é de grande extensão e tem várias estratégias argumentativas em si. Contudo, devido ao espaço determinado para este trabalho, destacam-se apenas os trechos que, de alguma maneira, têm afinidade com as tirinhas analisadas.

Sem um autor definido, o texto mostra-se como uma "voz coletiva" daqueles que têm "conhecimento de causa", pois foi publicado no site da Associação dos Profissionais dos Correios (ADCAP). Ou seja, o fato de representar os profissionais que trabalham na instituição já se interpõe como um "discurso de autoridade" (estratégia de legitimação). O artigo tem como objetivo principal, conforme diz o título, elencar alguns dos argumentos usados pelo governo a favor da privatização da estatal e refutá-los, apresentando contra-argumentos. Em seus parágrafos iniciais, além de contextualizar o tema (1), justifica a abordagem do assunto (2) e apresenta a tese principal (3) a ser defendida ao longo do texto:

(1) Num momento em que a privatização parece voltar ser uma das maiores bandeiras defendidas por esse novo governo e os Correios voltaram ao noticiário através de declarações sobre a intenção de privatizar a estatal, (2) um debate mais aprofundado sobre o tema se faz extremamente necessário para que sejam esclarecidos os argumentos utilizados para justificar tal feito. Em meio a tantas versões sobre as razões para a privatização dos Correios, é de essencial importância que se esclareçam as verdades sobre alguns argumentos sem embasamento concreto que vêm sido utilizados por quem se coloca a favor da privatização da estatal. [...] (3) os Correios possuem características e qualidades que justificam plenamente sua manutenção como organização pública, diferentemente de muitas outras.

Contudo, apesar de a tese principal defender a manutenção dos Correios enquanto estatal, em um recurso de modalização ${ }^{10}$, para "proteger sua face”, o texto não inclui as outras instituições públicas em seu discurso, quando diz que "os Correios possuem características e qualidades que justificam plenamente sua manutenção como organização pública, diferentemente de muitas outras".

Quanto à construção de argumentos, percebe-se semelhanças entre o que se diz em sentido favorável e contrário à privatização nos dois gêneros apresentados, revelando que algumas afirmações já estão arraigadas no discurso dos grupos a favor da privatização e fazem parte de seu imaginário. O principal argumento utilizado é o de que "Quando privatizar, vai melhorar" (lembrando que, na tirinha, a fala de Pudim está entre aspas, representando uma voz

\footnotetext{
${ }^{10}$ Segundo Charaudeau (1992, p. 571-3), a modalização é parte do fenômeno linguístico da enunciação, que indica a posição assumida pelo locutor e pelo interlocutor no ato de linguagem e revela uma intenção de comunicação, dependendo da situação. Longe de ser uma categoria puramente formal, a modalização é uma construção conceitual e, para o autor, pode encontrar-se no implícito do discurso.
} 


\title{
PERcursos Linguísticos • Vitória (ES) •v. 11 •n. 29 • 2021 • ISSN: 2236-2592 • Dossiê temático $\bullet O$ texto na pesquisa e no ensino: conhecimentos, práticas e desafios na contemporaneidade •
}

coletiva). No artigo da ADCAP, encontram-se as seguintes afirmações acerca da posição do governo:

\begin{abstract}
Tarifas foram congeladas sem necessidade, dividendos foram retirados em excesso, gerando, assim, um enorme desequilíbrio econômico que afetou a estatal. Deste modo, decisões de gestões anteriores no Governo Federal, aliadas à onda do neoliberalismo que acomete o atual governo, o que se apresenta agora como solução é a privatização dos Correios. (Parágrafos 2-3)

[...] [O] governo prega que as privatizações seriam mais uma das soluções para a economia do país. [...] "Autoridades do governo se utilizam de falácias para sustentar uma narrativa de uma empresa falida, ineficiente, corrupta, deficitária, quando a realidade é justamente outra, bem diferente do que está sendo propalado, demonstrando, no mínimo, total desconhecimento da empresa, de seu negócio, de sua capacidade, de seu faturamento. (Parágrafo 6)

A busca incessante em se desfazer de empresas estatais marginaliza a busca por dados de efetividade concretos e exclui do debate público novos modelos de gestão para a empresa prosperar. (Parágrafo 7)
\end{abstract}

Na tira, a fala de Pudim, portanto, ecoa as falas daqueles que fazem parte de seu grupo, com a mesma identidade coletiva. O trecho "[a]utoridades do governo se utilizam de falácias para sustentar uma narrativa de uma empresa falida, ineficiente, corrupta, deficitária" resume todos os argumentos utilizados pelos grupos liberais para justificar a privatização da estatal. Desse modo, o artigo procura, por meio de argumentos sólidos, desfazer o que eles chamam de "argumentos sem embasamento" e "falácias"11".

Os argumentos utilizados pela Associação assemelham-se àqueles utilizados por Armandinho, sendo que, no artigo, fala-se especificamente da estatal. No quadro 2, é possível comparar os contra-argumentos utilizados na tirinha e no artigo para refutar o discurso da privatização e perceber a semelhança de ideias: a instituição é precarizada pelo governo com o intuito de privatizá-la; as empresas privadas têm interesse na privatização visando somente ao lucro; a privatização restringe o público e privilegia os mais favorecidos; a privatização aumenta a segregação social e tira o benefício dos mais necessitados.

Quadro 2: Comparação de argumentos contrários à privatização

\begin{tabular}{|c|l|}
\hline Tirinha (Armandinho) & \multicolumn{1}{c|}{ Artigo (Correios/ADCAP) } \\
\hline $\begin{array}{c}\text { "A pracinha foi abandonada..." (Há } \\
\text { uma precarização da instituição } \\
\text { pública com o intuito de desqualificá- } \\
\text { la e depois vendê-la). }\end{array}$ & $\begin{array}{l}\text { Tarifas foram congeladas sem necessidade, dividendos foram } \\
\text { retirados em excesso, gerando, assim, um enorme desequilíbrio } \\
\text { econômico que afetou a estatal. (Parágrafo 2). } \\
\text { "O que sofremos hoje é por conta do contingenciamento, o que } \\
\text { prejudicou demais a imagem da empresa, já que perdemos pessoal } \\
\text { qualificado e investimentos deixaram de ser feitos" (Parágrafo 12). }\end{array}$ \\
\hline
\end{tabular}

\footnotetext{
${ }^{11}$ Plantin (2008, p. 120) define falácias como "um discurso viciado e vicioso, que se parece com um raciocínio válido: joga-se com o sentido das palavras, toma-se o efeito pela causa, responde-se bem a uma pergunta, mas não à pergunta feita, a conclusão só faz reformular as premissas etc.”.
} 


\section{PERcursos Linguísticos • Vitória (ES) •v. 11 •n. 29 • 2021 • ISSN: 2236-2592 • Dossiê temático $\bullet O$ texto na pesquisa e no ensino: conhecimentos, práticas e desafios na contemporaneidade •}

\begin{tabular}{|c|c|}
\hline $\begin{array}{c}\text { "Mesmo? Eu não sabia que as } \\
\text { empresas eram tão boazinhas, pudim!" } \\
\text { (As empresas privadas só visam ao } \\
\text { lucro, não fazem nada sem algo em } \\
\text { troca). }\end{array}$ & $\begin{array}{l}\text { O fato é que o interesse de grupos privados é apenas por agências } \\
\text { que abrangem capitais ou grandes municípios, que apresentam } \\
\text { serviços superavitários, deixando de lado as agências localizadas em } \\
\text { cidades onde a atividade não é lucrativa. Mais uma vez cabe lembrar } \\
\text { que essas localidades são atendidas exclusivamente pelos Correios e, } \\
\text { o mais importante, sem aporte de recursos da União. (Parágrafo 16) }\end{array}$ \\
\hline $\begin{array}{l}\text { "Mas é a gente que usa, Pudim! Se } \\
\text { cobrarem entrada na pracinha, muita } \\
\text { gente não vai poder usar! Não é toda } \\
\text { criança que tem dinheiro, Pudim!” } \\
\text { (Isso vai restringir o público e } \\
\text { prejudicar principalmente os mais } \\
\text { pobres, que não têm condições para } \\
\text { custear a atividade.). }\end{array}$ & $\begin{array}{l}\text { Caso a empresa venha mesmo a ser privatizada, a tendência é que o } \\
\text { custo do serviço postal aumente (Parágrafo12). Mais uma vez, cabe } \\
\text { lembrar que, para várias pessoas, os Correios são a única alternativa } \\
\text { para envio de documentos, encomendas e recebimento de contas. } \\
\text { Devido ao seu alcance, os Correios ajudam na prestação de serviços } \\
\text { financeiros e na inclusão bancária de milhões de brasileiros que } \\
\text { vivem em localidades carentes e que não precisam mais se deslocar } \\
\text { a cidades vizinhas para fazer operações bancárias. (Parágrafo 14) }\end{array}$ \\
\hline $\begin{array}{c}\text { "Como assim?" (Isso aumentará a } \\
\text { segregação social e tirará o benefício } \\
\text { dos mais necessitados, que também têm } \\
\text { direito ao lazer). }\end{array}$ & $\begin{array}{l}\text { No caso de privatização, Jaílson Pereira, presidente da AACB } \\
\text { (Associação dos Analistas de Correios do Brasil), acredita que de } \\
\text { imediato o país viveria um apagão postal. "O brasileiro no geral não } \\
\text { tem conhecimento de que os Correios são a única empresa que está } \\
\text { nos mais de } 5500 \text { municípios do país. Será que se privatizarem os } \\
\text { Correios vão manter o trabalho nas agências de pequeno porte, nas } \\
\text { cidades remotas, que não dão lucro?" (Parágrafo 17) }\end{array}$ \\
\hline
\end{tabular}

Fonte: Criação nossa.

Como conclusão, retomando a tese de que "os Correios possuem características e qualidades que justificam plenamente sua manutenção como organização pública”, o artigo reforça que:

Os Correios, com sua infraestrutura pronta e plenamente operacional, constituem uma plataforma de logística, de comunicações e de atendimento importante para a vida dos cidadãos, das empresas e dos governos. (Parágrafo 22)

Cuidar bem dessa infraestrutura, potencializando sua utilização em benefício dos brasileiros, é uma missão relevante para o Governo Federal, que deve enxergar os Correios como uma peça fundamental para o desenvolvimento de um país como o Brasil, à sua disposição, em todo o território nacional. (Parágrafo 23)

Esses são apenas alguns dos aspectos que podem ser observados em uma análise linguístico-discursiva, que considera o texto em seus diferentes gêneros, materializações e situações de uso. Enfim, as estratégias argumentativas discutidas até aqui podem ser facilmente abordadas em sala de aula, levando os alunos a refletirem sobre a construção textual e a perceberem que, conforme aponta Fiorin (2016, p. 9),

Se a sociedade é dividida em grupos sociais, com interesses divergentes, então os discursos sempre são o espaço privilegiado de luta entre vozes sociais, o que significa que são precipuamente o lugar da contradição, ou seja, da argumentação, pois a base de toda a dialética é a exposição de uma tese e sua refutação.

Ressalta-se, portanto, a importância de se desenvolver um trabalho com o texto que considere a diversidade de conhecimentos dos sujeitos e da situação comunicativo-interacional. 


\title{
PERcursos Linguísticos • Vitória (ES) •v. 11 •n. 29 • 2021 • ISSN: 2236-2592 • Dossiê temático $\bullet O$ texto na pesquisa e no ensino: conhecimentos, práticas e desafios na contemporaneidade •
}

\section{Aprender a argumentar, aprender a conviver: o texto na sala de aula para o exercício da cidadania (ou Considerações finais)}

\begin{abstract}
Os jovens têm se engajado cada vez mais como protagonistas da cultura digital, envolvendo-se diretamente em novas formas de interação multimidiática $e$ multimodal e de atuação social em rede, que se realizam de modo cada vez mais ágil. Por sua vez, essa cultura também apresenta forte apelo emocional e induz ao imediatismo de respostas e à efemeridade das informações, privilegiando análises superficiais e o uso de imagens e formas de expressão mais sintéticas, diferentes dos modos de dizer e argumentar característicos da vida escolar. Todo esse quadro impõe à escola desafios ao cumprimento do seu papel em relação à formação das novas gerações.
\end{abstract}

BNCC (BRASIL, 2017, p. 61)

Geraldi (1995, p.135), em seu clássico livro Portos de passagem, já apontava que o texto deveria ser o "ponto de partida (e ponto de chegada) de todo o processo ensino/aprendizagem da língua", já que é nele que a língua (objeto de estudos) se revela em sua totalidade. Além disso, é consenso entre professores e pesquisadores que o texto deve ser considerado preferencialmente em seu contexto real de produção, para que sejam percebidas todas as nuances da construção da significação. Retomando os pressupostos da Semiolinguística, na compreensão de um texto, é preciso ir além do sentido de língua (superfície linguística), observando-se o contrato de comunicação, as estratégias utilizadas e os imaginários envolvidos para que se alcance o sentido de discurso, por meio das inferências.

$\mathrm{Na}$ sociedade atual, principalmente no país polarizado no qual vivemos, em que as pessoas - alimentadas por uma avalanche de informações "fast-food" veiculadas pelas redes sociais - têm dificuldade de discernir o que é fato e opinião, ciência e senso comum, o jogo argumentativo ganha novos contornos. O debate público tem sido cada vez mais explorado, nem sempre de forma racional, em que as partes expressam seus argumentos de modo a defender sua tese. Na maior parte das vezes, principalmente em temas polêmicos, os lados, de forma irredutível, inflamam-se ao defender sua ideologia, buscando atingir um terceiro que venha a aderir a sua tese e somar-se ao grupo. Vivemos tempos difíceis, em que a argumentação por vezes se transforma em insultos e acusações, desqualificando o outro.

Se queremos um país mais democrático e um mundo melhor, temos de começar aprendendo a ouvir o outro e a respeitá-lo, mesmo que discordemos de seus argumentos. O debate pressupõe dois lados que apresentam suas ideias, em busca de um consenso e uma solução comum, e não uma via de mão única em que só um extremo tem razão. Por isso, o ensino de argumentação na escola torna-se cada vez mais urgente e necessário, não somente com o objetivo de preparar os alunos para provas de acesso ao nível superior, mas também de 


\section{PERcursos Linguísticos • Vitória (ES) •v. 11 •n. 29 • 2021 • ISSN: 2236-2592 • Dossiê temático $\bullet O$ texto na pesquisa e no ensino: conhecimentos, práticas e desafios na contemporaneidade •}

instrumentalizá-los para saber expressar suas opiniões respeitosamente e, além de tudo, não serem facilmente manipulados por informações de fonte duvidosa ou discursos passionais. Para isso, é preciso levar para a sala de aula uma diferente gama de gêneros argumentativos, para além dos canônicos, visando à formação de cidadãos críticos, conscientes de suas ações na vida em sociedade.

\section{Referências}

BRASIL. Ministério da Educação. Secretaria da Educação Básica. Base Nacional Comum Curricular. Brasília, DF: MEC, 2017.

DEMO, Pedro. O educador e a prática da pesquisa. Ribeirão Preto: Editora Alphabeto, 2009.

DOLZ, Joaquim; SCHNEUWLY, Bernard. Gêneros orais e escritos na escola. Campinas, SP: Mercado das Letras, 2004.

CAVALCANTE, Mônica et al. Linguística Textual e argumentação. São Paulo: Pontes, 2020.

CHARAUDEAU, Patrick. Grammaire du sens et de l'expression. Paris, Hachette, 1992.

CHARAUDEAU, Patrick. Discurso das mídias. Trad. Angela M. S. Corrêa. São Paulo: Contexto, 2006a.

CHARAUDEAU, Patrick. Discurso político. Trad. Angela M. S. Corrêa. São Paulo: Contexto, 2006b.

CHARAUDEAU, Patrick. Linguagem e discurso: modos de organização. São Paulo: contexto, 2008.

CHARAUDEAU, Patrick. Identidade social e identidade discursiva: o fundamento da competência comunicacional. In: PIETROLUONGO, Márcia (Org.). O trabalho da tradução. Rio de Janeiro: Contra Capa, 2009, p. 309-326.

CHARAUDEAU, Patrick. Identidade linguística, identidade cultural: uma relação paradoxal. In: LARA, Glaucia Proença.; LIMBERTI, Rita Pacheco. (Orgs.). Discurso e (Des)igualdade social. São Paulo: Contexto, 2015. p. 13-29.

CHARAUDEAU, Patrick. A conquista da opinião pública: como o discurso manipula as escolhas públicas. Trad. Angela M. S. Corrêa. São Paulo: Contexto, 2016.

CHARAUDEAU, Patrick. Compréhension et interpretation: interrogations autour de deux modes d'appréhension du sens dans les sciences du langage. In: ACHARD-BAYLE, Guy; GUÉRIN, Maximilen; KLEIBER; Georges; KRYLYCHIN, Marina. (Org.). Les sciences du langage et la question de l'interprétation (aujourd'hui). Limoges: Les Éditions Lambert-Lucas, 2018, p.21-55.

FIORIN, José Luiz. Argumentação. São Paulo: Contexto, 2016. 
PERcursos Linguísticos • Vitória (ES) •v. 11 •n. 29 • 2021 • ISSN: 2236-2592 • Dossiê

temático $\bullet O$ texto na pesquisa e no ensino: conhecimentos, práticas e desafios na contemporaneidade •

GERALDI, João Wanderley. Portos de passagem. São Paulo: Martins Fontes, 1995.

KOCH, Ingedore Villaça G. A inter-ação pela linguagem. 4. ed. São Paulo: Cortez, 1998.

KOCH, Ingedore Villaça G; ELIAS, Vanda Maria. Escrever e argumentar. São Paulo: Contexto, 2017.

MENEZES, William Augusto. Estratégias discursivas e argumentação. In: LARA, Glaucia Muniz Proença (Org.). Lingua(gem), texto e discurso: entre a reflexão e a prática. Rio de Janeiro: Lucerna; Belo Horizonte, MG: FALE/UFMG, 2006.

NICOLAU, Vitor; MAGALHÃES, Henrique. As tirinhas e a cultura da convergência: um estudo sobre a adaptação deste gênero dos quadrinhos às novas mídias. In: LUIZ, Lucio (Org.). Os quadrinhos na era digital: HQtrônicas, webcomics e cultura participativa. Nova Iguaçu, RJ: Marsupial, 2013.

PERELMAN, Chaïm; OLBRECHTS-TYTECA, Lucie. Tratado da argumentação: a nova retórica. 2. ed. São Paulo: Martins Fontes, 2005.

PLANTIN, Christian. A argumentação: história, teorias, perspectivas. Trad. Marcos Macionilo. São Paulo: Parábola, 2008.

REBELLO, Ilana da Silva. A Semiolinguística vai para a escola. In: XAVIER, Glayci; REBELLO, Ilana; MONNERAT, Rosane (Orgs.) Semiolinguística aplicada ao ensino. São Paulo: Contexto, 2021. 